\title{
A POTÊNCIA E A COMPLEXIDADE DE UM FAZER DIALÓGICO: DESAFIOS DA FORMAÇÃO E DA ATUAÇÃO DE EDUCADORAS(ES) SOCIAIS
}

\section{LA POTENCIA Y LA COMPLEJIDAD DE UNA ACCIÓN DIALÓGICA: RETOS DE LA FORMACIÓN Y ACTUACIÓN DE LAS EDUCADORAS Y LOS EDUCADORES SOCIALES}

\author{
THE POTENCY AND COMPLEXITY OF A DIALOGICITY: CHALLENGES IN THE \\ FORMATION AND PERFORMANCE OF SOCIAL EDUCATORS
}

\author{
Juliana dos Santos ROCHA ${ }^{1}$ \\ Marlene ROZEK ${ }^{2}$
}

\begin{abstract}
RESUMO: Este artigo originou-se de uma pesquisa e trata da constituição subjetiva de educadoras(es) sociais que se posicionam dialogicamente diante de suas(seus) educandas(os), tendo em vista a necessidade de um espaço que pensa e discute os processos de ensino e aprendizagem na Educação Social. A discussão, feita a partir das construções interpretativas da pesquisa, de cunho qualitativo, permite compreender que as posturas dialógicas dos participantes estão relacionadas a configurações e sentidos subjetivos que se expressam pelo reconhecimento da humanidade do outro. Para tanto, foi necessário que os participantes superassem as produções da subjetividade social dominante no Brasil a respeito de suas(seus) educandas(os), que, muitas vezes, as(os) coloca em um lugar de "não saber", de incapacidade. Uma construção que direciona a reflexão à necessidade de uma formação que precisa ser pensada e estruturada em uma perspectiva mais humana e menos tecnicista, de modo a promover posicionamentos mais críticos e conhecimentos históricos e conceituais articulados com a prática.
\end{abstract}

PALAVRAS-CHAVE: Educação Social. Educadoras(es) sociais. Subjetividade. Aprender. Ensinar.

RESUMEN: El artículo tiene su origen en una investigación y trata de la constitución subjetiva de los educadores sociales que se posicionan dialógicamente ante sus alumnos, ante la necesidad de un espacio que piense y discuta los procesos de enseñanza y aprendizaje en el contexto de la Educación Social. La discusión, a partir de las construcciones interpretativas de la investigación, de carácter cualitativo, permite comprender que las posturas dialógicas de los participantes están relacionadas con configuraciones subjetivas y significados que se expresan a través del reconocimiento de la humanidad del otro; para eso, era necesario que los participantes pudieran superar las producciones de la subjetividad social dominante en Brasil con respecto a sus (sus) estudiantes, quienes, muchas veces, los colocan en un lugar de

\footnotetext{
1 Fundação Projeto Pescar (FPP), Porto Alegre - RS - Brasil. Pedagoga, Qualificação e Aprimoramento. Doutorado em Educação (PUCRS). ORCID: https://orcid.org/0000-0001-6923-2107. E-mail: julianarocha@projetopescar.org.br

${ }^{2}$ Pontifícia Universidade Católica do Rio Grande do Sul (PUCRS), Porto Alegre - RS - Brasil. Professora da Escola de Humanidades. Doutorado em Educação (UFRGS). ORCID: http://orcid.org/0000-0001-8740-6166. Email: marlene.rozek@pucrs.br
}

RIAEE - Revista Ibero-Americana de Estudos em Educação, Araraquara, v. 15, n. esp. 3, p. 2411-2428, nov., 2020. E-ISSN: 1982-5587 
"no saber", de incapacidad. Una construcción que dirige la reflexión a la necesidad de una formación que necesita ser pensada y estructurada en una perspectiva más humana y menos técnica, para promover posiciones más críticas y conocimientos históricos y conceptuales articulados con la práctica.

PALABRAS CLAVE: Educación Social. Educadores sociales. Subjetividad. Aprender. Enseñar.

ABSTRACT: This paper has origin from a research and it is about the subjective constitution of social educators who are dialogically positioned in relation with their students, considering the need for a space that thinks and discusses the teaching and learning processes in Social Education. Based on the interpretive constructions of the research, which has a qualitative nature, the discussion allows us to understand that the participants' dialogical postures are related to subjective configurations and meanings that are expressed through the recognition of the other's humanity. For that, it was necessary that the participants overcome the productions of the dominant social subjectivity in Brazil regarding their students, that often puts them in a place of inability. A construction that directs the reflection to the necessity for formation that must be thought and structured in a more humane and less technical perspective, to promote critical positions, historical and conceptual knowledge articulated with practice.

KEYWORDS: Social education. Social educators. Subjectivity. Learn. Teach.

\section{Introdução: iniciando o percurso}

O presente artigo é resultado de uma pesquisa de doutoramento em Educação, concluída em março de 2020. A investigação buscou compreender como se constituem subjetivamente educadoras(es) sociais que se posicionam dialogicamente diante de suas(seus) educandas(os), tendo em vista a necessidade da instauração de um espaço que pensa e discute os processos de ensino e aprendizagem na Educação Social e, consequentemente, as possibilidades e necessidades de formação desses profissionais. Tal investigação originou-se da pesquisa de mestrado em Educação que se dedicou a compreender os sentidos subjetivos produzidos acerca da aprendizagem por adolescentes que participavam dos serviços oferecidos pela Política de Assistência Social em uma Organização da Sociedade Civil (OSC) de Porto Alegre, capital do Rio Grande do Sul, Brasil. A pesquisa, concluída em 2016, suscitou o desejo de compreender como se constituem educadoras(es) sociais que surgiram nas falas dos adolescentes como aqueles com os quais eles conseguiam construir um espaço de diálogo que favorecia suas aprendizagens, que permitia que eles se sentissem capazes de aprender e que aprendessem de fato. 
Desse modo, este artigo trata da constituição subjetiva de uma educadora e de um educador social, Fiona e Watusi ${ }^{3}$, que participaram de dinâmicas conversacionais, organizadas em seis encontros com cada um deles, guiadas pelas seguintes perguntas: como as vivências pessoais e profissionais se configuram subjetivamente na experiência de ser educador(a) social? Como as configurações subjetivas de educadoras(es) sociais se expressam em posicionamentos pessoais e profissionais frente às(aos) educandas(os) por elas(es) atendidas(os)? Quais crenças sobre aprendizagem apresentam as(os) educadoras(es) sociais? Como as(os) educadoras(es) percebem o aprender das(os) educandas(os)? A partir dessas questões, objetivou-se compreender melhor a potência e a complexidade de um fazer dialógico e os desafios da atuação e da formação desses trabalhadores.

Assim, este texto busca articular conhecimentos sobre subjetividade, aprendizagem e Educação Social, com o intuito de gerar inteligibilidade sobre o campo da Educação Social, contribuindo para a ampliação de importantes reflexões em âmbito nacional. O recorte proposto trata sobre a potência e a complexidade de uma postura ética que promove a construção de um espaço dialógico na Educação Social, refletindo acerca dos desafios da formação e da atuação de educadoras(es) sociais para a constituição dessa postura.

Para tanto, o artigo está organizado do seguinte modo: uma introdução, que visa a situar o leitor sobre como surgem as reflexões propostas; uma segunda parte, que se dedica a explicitar os caminhos metodológicos da investigação da qual emerge este texto; após, o leitor encontrará uma articulação sintética das bases teóricas da pesquisa, que versam sobre subjetividade, aprendizagem e Educação Social, com um posicionamento que defende a importância desses conceitos para a ampliação dos conhecimentos científicos sobre o campo da pesquisa; e, por fim, são apresentadas as reflexões que surgem a partir da construção da informação, a interpretação das pesquisadoras sobre os diálogos que se estabeleceram com os participantes da pesquisa, visando a refletir sobre posturas e fazeres dialógicos de educadoras(es) sociais.

Como caminhos apontados, possibilidades de desdobramentos e provocações, considera-se que um fazer dialógico no âmbito da Educação Social, por educadoras(es) sociais, consiste em posturas e práticas que promovam a participação efetiva das(os) educandas(os), respeitem sua humanidade, suas pautas e saberes, considerando-as(os) capazes de aprender e de ensinar, um processo que se mostra potente para a promoção, para a defesa e para a garantia de direitos e a emancipação do público ao qual atende. Para tanto, o desafio é oportunizar processos formativos de qualidade, mais humanos e menos tecnicistas, que promovam uma

${ }^{3}$ Nomes fictícios escolhidos pelos participantes no decorrer da pesquisa.

RIAEE - Revista Ibero-Americana de Estudos em Educação, Araraquara, v. 15, n. esp. 3, p. 2411-2428, nov., 2020. E-ISSN: 1982-5587 
série de conhecimentos articulados com experiências no campo, entre os quais se destacam, de modo introdutório: conhecimentos sobre aprendizagem como um processo humano, conhecimentos históricos sobre as expressões da questão social e conhecimentos e experiências estéticas diversas, que confrontem as construções sociais hegemônicas.

\section{Caminhos metodológicos: Epistemologia Qualitativa e Metodologia Construtiva- interpretativa}

A investigação da qual surge esta reflexão trata-se de uma pesquisa de cunho qualitativo, com base nos pressupostos da Epistemologia Qualitativa, proposta pelo psicólogo cubano Fernando González Rey, cujos princípios norteiam estudos que se propõem a estudar o fenômeno da subjetividade. Nesse sentido, o autor destaca que a ciência é conhecimento e explicação, não mera descrição do empírico, e, quando se trata de fenômenos como a subjetividade, construir conhecimento científico, gerar zonas de inteligibilidade, requer apreender e interpretar uma expressão psicológica que é dinâmica, processual e dialética (GONZÁLEZ REY, 2017). Salienta-se, então, que a Epistemologia Qualitativa entende que a ciência tem caráter processual e é produzida a partir da interação ativa do ser humano, que carrega consigo uma história, que trata de um objeto igualmente histórico e mutável, integrado simultaneamente em múltiplos sistemas de relação com a realidade.

Nesse complexo sistema, o indivíduo que participa de uma investigação não é passivo, não é um mero informante. Tampouco a(o) investigadora(or) utiliza-se de uma informação para simplesmente significar uma realidade. A informação vai sendo construída por ambos em uma perspectiva de dialogicidade. Espaços de inteligibilidade produzidos a partir da pesquisa científica, mas que jamais são tidos como verdade final, não se esgotam em si mesmos e abrem espaço para o aprofundamento e para novas construções teóricas.

A Metodologia Construtiva-interpretativa enfatiza sua natureza teórica. Desse modo, a pesquisa orienta-se para o desenvolvimento de modelos compreensivos a respeito do que se propõe a estudar, já que parte do princípio de que o conhecimento é um processo de construção, legitimado pela capacidade de produção de novas concepções "no curso da confrontação do pensamento do pesquisador com a multiplicidade de eventos empíricos coexistentes no processo investigativo" (GONZÁLEZ REY, 2005, p. 7). Assim, o conhecimento não é uma realidade pronta para ser conhecida e ordenada de acordo com categorias universais. Ademais, outro princípio importante dessa perspectiva é considerar a teoria como um modelo teórico em desenvolvimento, não como uma verdade pronta e estática, assim, "a significação de cada 
registro empírico durante o desenvolvimento de um sistema teórico é, necessariamente, um ato de produção teórica, pois é inseparável do sistema teórico" (GONZÁLEZ REY, 2005, p. 7).

Desse modo, no curso da pesquisa, a(o) pesquisadora(or) constrói a informação a partir de indicadores ${ }^{4}$ que surgem das dinâmicas conversacionais, ou seja, faz um esforço interpretativo para gerar inteligibilidade sobre as configurações e os sentidos subjetivos que se relacionam com seu problema de pesquisa - nesse caso, como se constituem subjetivamente educadoras(es) sociais com posturas dialógicas diante de suas(seus) educandas(os)? O encadeamento de ideias, de indicadores, permite a(ao) pesquisadora(or) construir algumas hipóteses de interpretação, que podem ser aprofundadas ou refutadas no processo da pesquisa, configurando-se no desdobramento teórico de acordo com o tema estudado.

Participaram da investigação uma educadora e um educador social, considerados pelos adolescentes participantes da pesquisa de mestrado e pela investigadora como aqueles que tinham posturas dialógicas diante de suas(seus) educandas(os), que potencializavam os processos de aprendizagem e de ensino nos seus contextos de trabalho. O campo da pesquisa teve duração de um ano e meio, com média de seis encontros com cada participante, além de mensagens com temáticas consideradas importantes de serem aprofundadas. Os encontros ocorreram como dinâmicas conversacionais provocadas por questões norteadoras sobre o fazer e o ser educadora(or) social e, nos encontros subsequentes, questões surgiram dos indicadores construídos a partir dos diálogos. Utilizou-se, ainda, como indutor de diálogo, o completamento de frases, atividade na qual se apresenta uma série de sentenças iniciadas para que o participante as complete (GONZÁLEZ REY, 2005), e a técnica projetiva psicopedagógica Par Educativo, que consiste em solicitar que a(o) participante desenhe uma cena com duas pessoas, uma ensinando e outra aprendendo (VISCA, 2002). Nos dois últimos casos, após a técnica, seguiuse a dinâmica conversacional.

\section{Subjetividade, aprendizagem e educação social: teorias em diálogo}

A subjetividade é aqui entendida como um fenômeno simbólico-emocional que se desenvolve na cultura em um movimento dialético entre individual e social, um conceito fundamentado na Teoria da Subjetividade, proposta por González Rey e colaboradores. Tal teoria (GONZÁLEZ REY; MITJÁNS MARTÍNEZ, 2017) tem base nos pressupostos da

${ }^{4}$ Os indicadores representam o esforço interpretativo do pesquisador, permitindo a tessitura de um conjunto de reflexões, em uma análise integrada das informações da pesquisa, podendo, no decorrer da construção da informação, pela coerência e pelo encadeamento entre os indicadores, desdobrar-se em hipóteses (GONZÁLEZ REY; MITJÁNS MARTÍNEZ, 2017).

RIAEE - Revista Ibero-Americana de Estudos em Educação, Araraquara, v. 15, n. esp. 3, p. 2411-2428, nov., 2020. E-ISSN: 1982-5587 
Psicologia Cultural-histórica de Vygotsky (1896-1934) e busca abrir caminho para uma nova compreensão dos processos subjetivos, uma visão mais complexa, que pensa a constituição e o desenvolvimento do indivíduo na cultura e que tenta superar dicotomias, tais como objetivo versus subjetivo, social versus individual, cognitivo versus afetivo.

Nesse marco teórico, a subjetividade deixa de ser um fenômeno intrapsíquico ou uma internalização linear e causal do social, e passa a ser considerada um sistema aberto, recursivo e complexo. Aberto porque se trata de uma produção que acontece durante toda a vida; recursivo porque, ao produzir subjetividade no momento vivido, o indivíduo reconfigura e produz novos sentidos subjetivos em uma trama que é composta pela experiência atual, mas que se entrelaça com experiências e produções anteriores (GONZÁLEZ REY; MITJÁNS MARTÍNEZ, 2017); e, complexa, não como algo difícil de ser compreendido, mas como uma qualidade que se expressa pelo caráter "desordenado, contraditório, plural, recursivo, singular, indivisível e histórico" (MITJÁNS MARTÍNEZ, 2005, p. 4) dos sistemas humanos.

A subjetividade, de acordo com a teoria, organiza-se em configurações subjetivas, as quais não são anteriores à experiência e nem mesmo determinantes dela, pelo contrário, "elas são a própria experiência como subjetividade vivida" (GONZÁLEZ REY, 2012a, p. 28). O indivíduo produz subjetividade ao organizar, de modo inconsciente, essas configurações subjetivas no decurso da experiência atual, correlacionando-a de modo desordenado com experiências do passado e com a produção de subjetividade social. Essa produção é geradora de emoções, crenças, representações, entre outros.

Em uma perspectiva dialética, a subjetividade abarca todos os processos humanos, desde os macrossociais até os individuais; não dialoga com atributos universais, mas compreende uma produção de sentidos subjetivos que não pode ocorrer separadamente do contexto e das complexas formas de organização social. "A subjetividade é da ordem do constituído, mas representa uma forma de constituição que, por sua vez, é permanentemente reconstituída pelas ações dos sujeitos dentro dos diversos cenários sociais em que atuam” (GONZÁLEZ REY, 2012b, p. 126), ou seja, as configurações subjetivas são sistemas abertos e em movimento.

Assim, é importante destacar que, nessa concepção, a subjetividade é um fenômeno com duas facetas: a subjetividade social e a subjetividade individual. $\mathrm{O}$ ser humano produz subjetividade em um movimento dialético entre essas duas perspectivas, ele é produtor de subjetividade social e é produzido por ela. A subjetividade produzida por uma pessoa nunca está separada do social, tampouco trata-se de uma apropriação linear da subjetividade social, há, nessa produção, a faceta da subjetividade individual (GONZÁLEZ REY; MITJÁNS MARTÍNEZ, 2017).

RIAEE - Revista Ibero-Americana de Estudos em Educação, Araraquara, v. 15, n. esp. 3, p. 2411-2428, nov., 2020. E-ISSN: 1982-5587 
Contudo, muitas vezes a produção de subjetividade individual, no sentido da possibilidade de criar caminhos subjetivos alternativos à subjetividade social, não é fácil e tende a exigir um trabalho psíquico intenso do indivíduo. Para González Rey e Mitjáns Martínez (2017, p. 54), “a subjetividade social é uma fonte constante de produção de sentidos subjetivos nas tramas de seus múltiplos personagens", ou seja, são crenças, valores, construções simbólicas em geral, que participam de forma ativa da produção de subjetividade dos indivíduos, os quais também produzem a subjetividade social. Cabe ressaltar, então, que a subjetividade social se expressa nas crenças, nos mitos, nas representações sociais, na moral, nas relações de poder, nas formas de funcionamento das instituições, nas hierarquias, na forma como o saber circula, nas ideologias, na qualidade dos diálogos que se caracterizam nos espaços, entre outros (GONZÁLEZ REY, 2002).

Nesse contexto, o aprender e o ensinar não ocorrem fora da produção de subjetividade, mas estão perpassados pelas ideias dicotômicas que fazem parte da representação do humano e, também, por crenças e valores que marginalizam populações em função da ideia de que esses processos estão relacionados apenas à escolarização (ROCHA, 2016). Historicamente, a escolarização se constitui para uma parcela específica da sociedade - as elites (JOHANN, 2008) -, promovendo, muitas vezes, a precarização do aprender e do ensinar relacionados àqueles que não se encaixam nos padrões exigidos ou que não cumprem os requisitos estandardizados das avaliações mais comuns desse tipo de Educação.

Ao compreender que as práticas educativas sociais são ações com intencionalidade pedagógica - pensadas e planejadas a partir de objetivos - , entende-se que o aprender e o ensinar são constituintes dessas práticas. Desse modo, ressalta-se que a concepção de aprendizagem, que também é base das reflexões aqui propostas, está relacionada a uma perspectiva que vem buscando entender o aprender como um processo humano, que ocorre desde o nascimento e por toda a vida humana; um processo característico da humanização, que permite a apropriação dos modos de vida, a partir da reprodução e da produção de humanidade (ROCHA; DI FRANCO, 2017), tendo em vista que "a condição humana compreende mais que as condições sob as quais a vida foi dada ao homem" (ARENDT, 2014, p. 10). O aprender torna-se, também, condição humana.

Nesse sentido, destaca-se o potencial de qualquer ser humano para aprender, considerando que, para viver no mundo, isso é necessário. Assim, defende-se, de antemão, que todas(os) aprendem, ainda que se apresentem algumas diferenças, dificuldades ou dificultadores no caminho, haja vista a heterogeneidade do próprio processo e do humano. É importante destacar que se compreende, também, que aprender e ensinar são dois processos

RIAEE - Revista Ibero-Americana de Estudos em Educação, Araraquara, v. 15, n. esp. 3, p. 2411-2428, nov., 2020. E-ISSN: 1982-5587 
distintos, que dialogam entre si, pois aprender exige poder ensinar e ensinar exige poder aprender. Quando os indivíduos podem circular nesses papéis, a tendência é que haja processos mais fluídos, com pessoas que se sentem mais capazes (ROCHA, 2016; ROCHA; LEMOS; ALVES, 2019).

O aprender e o ensinar são processos relacionais, pois ocorrem a partir da relação humana, das relações historicamente construídas e culturalmente localizadas, em um processo essencialmente subjetivo, quando se considera que a subjetividade se constitui em um movimento dialético entre social e individual, configurando-se na experiência vivida. Ou seja, significa que todo conhecimento é produzido, perpetuado ou transformado, dentro de uma história e de uma cultura. Nesse sentido, González Rey (2020) salienta que os movimentos intelectuais, a produção de ciência e de conhecimento, são sempre históricos e, portanto, humanos, não ocorrendo independentemente das crenças, das realidades humanamente produzidas e da subjetividade social. Aquilo que se escolhe ensinar, ou quando se escolhe para quem ensinar, é fruto de uma construção histórico-cultural.

Portanto, entende-se que aprender e ensinar não são processos meramente cognitivos e individuais, mas ocorrem na relação humana e, por isso, deles fazem parte uma multiplicidade de aspectos que constituem o humano. O aprender e o ensinar se constituem, por sua vez, por afetos, emoções, subjetividades, contextos, corpos, estruturas cognitivas, entre outras questões possíveis.

Ampliada a perspectiva de aprendizagem e de ensino para além dos muros da escola e dos conteúdos preestabelecidos e hierarquizados das grades curriculares da Educação Básica, fica ainda mais evidente a concretização dos verbos "aprender" e "ensinar" nos espaços de Educação Social. Conforme já explicitado na introdução, tem-se compreendido a Educação Social como espaço de práticas educativas com intencionalidade pedagógica, a qual varia de acordo com a proposta específica que se concretiza, mas, que, de modo geral, tem centralidade nos processos de ensinar e aprender, que se desenvolvem com populações em eminência ou em situação de violação de direitos, tendo como finalidade a promoção do desenvolvimento integral das pessoas as quais atende, bem como a promoção, a defesa e a garantia de direitos e o acesso a oportunidades desses indivíduos, respeitando sua capacidade de decidir sobre si mesmos e de pensar sobre sua ação no mundo (ROCHA, 2020).

Trata-se de uma compreensão da Educação Social possível no momento, sem a pretensão de cunhar-se um conceito definitivo com peso de verdade estática. Nesse sentido, de acordo com Úcar (2016, p. 31), “el atributo de estar en construcción es más esencial que conyuntural. Si lo social es móvil, dinámico y está en continuo cambio, la pedagogía social y 
la educación que se ocupan de él no pueden ser sino móviles, dinámicas y sometidas a continuos procesos de cambios". Ademais, em uma publicação mais atual (ÚCAR, 2018), o autor salienta que, de forma especial, na última década, em virtude das vulnerabilidades e das necessidades vitais, derivadas das situações de guerra e de pobreza as quais as pessoas estão submetidas, desenham-se novos espaços e âmbitos de necessidades e atuação que obrigam reflexões e (re)planejamentos das ações no campo social, o que, uma vez mais, remete a esse status de construção permanente.

Contudo, compreende-se que o público-alvo da Educação Social não são somente as populações em situação de pobreza, pois a Educação Social se compromete a atuar para diminuir os efeitos drásticos das desigualdades e injustiças sociais impostas pela organização social, tendo em vista desenvolver, juntamente com as pessoas, alternativas para melhorar a vida de indivíduos, famílias, comunidades ou grupos (DEL POZO SERRANO, 2017). Assim, pode se referir, por exemplo, à construção de paz com diferentes públicos, ao trato de situações de violências em suas diferentes expressões e com diferentes indivíduos e a iniciativas que se dedicam a promover e a defender os direitos humanos com todos os públicos.

Atualmente, tais práticas têm sido desenvolvidas no Brasil a partir de políticas públicas, em sua maioria, da área da Assistência Social, como, por exemplo, Serviço de Convivência e Fortalecimento de Vínculos (SCFV), Acolhimento Institucional, Abordagem Social, entre outros, mas também pela área da Educação, como é o caso do Programa Mais Educação - como forma de promoção de Educação Integral (ZUCCHETTI; SEVERO, 2020) - e do Programa Mais Cultura nas Escolas (SOWA; ROSA, 2014), uma proposta interministerial das pastas da Cultura e da Educação. Outros setores, como a Política de Segurança Pública, também instituem políticas públicas que se consolidam com a Educação Social, como é o caso do Programa de Oportunidade e Direitos (POD), cofinanciado pelo Banco Interamericano de Desenvolvimento (BID), instaurado no Estado do Rio Grande do Sul (SANTOS; PAZINATO; NASCIMENTO; DONATO; ENGELMAN, 2019), e pelo antigo Ministério do Trabalho, agora Secretaria do Trabalho, que de modo intersetorial com a Assistência Social, institui e organiza a Aprendizagem Socioprofissional.

Nesse escopo, considera-se que as(os) trabalhadoras(es) da área da Educação Social são educadoras(es) sociais (PEREIRA, 2016). Elas(es) têm, como parte do seu fazer, a responsabilidade de pensar e planejar ações, com intencionalidade pedagógica, que variam de acordo com o serviço que executam, mas que, de modo geral, visam à diminuição dos impactos 
das injustiças sociais, a promoção, defesa e garantia dos direitos humanos e a emancipação ${ }^{5}$ do público que acessa a Educação Social. De modo geral, tal trabalho ocorre em parceria com outros profissionais que, em funções distintas, também desenvolvem sua prática em prol da justiça social.

Ao compreender a dimensão pedagógica do fazer de educadoras(es) sociais, ao pensar o aprender e o ensinar de modo mais amplo e, portanto, parte das práticas educativas sociais, assim como um processo complexo e relacional, fica evidente a importância do trabalho de educadoras(es) sociais no contexto atual, principalmente ao se considerar a forte retração das políticas públicas que visam ao enfrentamento das desigualdades sociais em contexto nacional. Nesse sentido, a produção de conhecimentos que possam contribuir para o desenvolvimento do campo da Educação Social é emergente.

\section{A potência e a complexidade de um fazer dialógico: desafios da formação e da atuação de educadoras(es) sociais}

Os diálogos com Fiona e Watusi, subsídio para a construção da informação em articulação com os construtos teóricos basilares da pesquisa, permitiram desenvolver algumas reflexões que foram inicialmente feitas na pesquisa de mestrado junto às(aos) adolescentes educandas(os) de Fiona e Watusi. Uma das questões que a análise do material apontava é que as(os) adolescentes da pesquisa, moradoras(es) da periferia de uma capital do país, público de políticas públicas de Assistência Social, tinham maior potencial para aprender quando esse processo era proposto por educadoras(es) sociais que se posicionavam dialogicamente diante delas(es), ou seja, seu trabalho pedagógico era organizado com base no diálogo, na escuta, na construção coletiva, na valorização de seus saberes, entre outras questões. Pretendeu-se, então, gerar inteligibilidade sobre como se constituíam subjetivamente essas(es) educadoras(es).

Uma questão que pode ser pensada a partir dos diálogos gerados com Fiona e Watusi é que há uma postura ética que se conforma nesse fazer que se convencionou chamar dialógico: Fiona e Watusi têm um profundo respeito pelas(os) suas(seus) educandas(os), pela sua humanidade.

Watusi, homem negro, educador de capoeira, estudante de Pedagogia, cresceu em uma família que cultiva a cultura africana, estuda sobre a temática. Sua concepção de mundo e gente

${ }^{5}$ Emancipação no sentido de que as pessoas se tornem capazes de refletir sobre a história e, ao fazê-lo, possam não reproduzir a barbárie, mas interrompê-la; uma emancipação que se relaciona com resistência e contestação do status quo (ADORNO, 1995).

RIAEE - Revista Ibero-Americana de Estudos em Educação, Araraquara, v. 15, n. esp. 3, p. 2411-2428, nov., 2020. E-ISSN: 1982-5587 
está muito articulada à produção de subjetividade social produzida pela cultura afro-brasileira. Nesse sentido, ele ressalta:

O importante não é ter, é ser. Na religião africana é ser mais um, compartilhar com o outro que também é. Trazendo esse ser para a educação é isso também, então, enquanto eu estou passando esse meu saber que eu tenho, que não me faz ser nem melhor nem pior, mas tem um saber diferente e é compartilhar meu saber, dai eu estou sendo contigo.

A partir deste e de outros trechos, é possível inferir que Watusi concebe o ser humano de forma bastante descolada da subjetividade social produzida em um sistema capitalista no qual o consumo, a competição e o mérito são centralidade. Ele vai, no seu processo de vida, com suas contradições, subjetivando o humano, suas(seus) educandas(os), de um modo bastante distanciado da subjetividade social que invisibiliza as populações mais pobres e majoritariamente negras. Ele as(os) reconhece em sua humanidade, o que permite a criação de um vínculo entre ensinante e aprendente, essencial para os processos de aprendizagem (ROCHA; LEMOS; ALVES, 2019).

Em um processo de vida distinto, mas que se aproxima, Fiona também faz movimentos subjetivos que se distanciam da subjetividade hegemônica. No caso dela, esse processo se inicia com sua experiência com o teatro, ainda criança. A partir da relação sensível com a arte e com o outro, tendo em vista que a arte se torna uma centralidade na vida de Fiona, ela desenvolve um olhar atento a(ao) sua(seu) educanda(o), um olhar que busca sempre ver o contexto, um olhar situado, crítico e sensível. Fiona diz em um dos encontros:

[...] A Monalisa, tá? O jovem é a Monalisa e a família, a escola e a comunidade são todo aquele fundo que até hoje ainda estão descobrindo. Então, a cada dia eu olho para esses quadrinhos ambulantes e penso: "O que tá ali que eu ainda não enxerguei?". Porque a arte tem isso, ela te faz olhar além da figura inicial, tu tens que olhar o todo: as cores, as formas, o movimento, o conjunto, a harmonia, o equilibrio, o ritmo. E, no fim, todo quadro é um quadro. Um diferente do outro, mas, um quadro cheio de história.

Esses modos de conceber suas(seus) educandas(os), que se constituíram nas experiências de Fiona e de Watusi - pela arte e pela cultura diversa, pelo tensionamento de suas formações, seus estudos, que promoveram reflexões e produções subjetivas importantes na vivência de ser educadora(or) social, fomentando a produção de caminhos subjetivos alternativos à subjetividade social hegemônica -, foram significativos para a promoção de espaços educativos sociais que viabilizavam processos de ensinar e de aprender pautados no papel ativo de todos na construção do conhecimento.

RIAEE - Revista Ibero-Americana de Estudos em Educação, Araraquara, v. 15, n. esp. 3, p. 2411-2428, nov., 2020. E-ISSN: 1982-5587 
Ressalta-se, assim, a importância de um fazer que pressupõe a participação e a importância da participação de todos no processo educativo. Nesse ínterim, destaca-se que Fiona e Watusi subjetivam a aprendizagem e o conhecimento de um modo que se aproxima muito com a construção teórica da pesquisa, que entende o aprender como um processo humano.

Fiona, ao falar sobre suas experiências de aprendizagem como aprendente ${ }^{6}$, ressalta uma aprendizagem da juventude, quando teve dificuldades na escola em virtude da metodologia rígida da professora:

[...] tem uma fórmula desgraçada que nunca dá certo e eu zerei uma prova. [...] Aí eu cheguei em casa desesperada e disse: "Mãe, olha só, eu zerei a prova de química, eu não entendi, eu não consigo entender isso aqui de jeito nenhum". Dai minha mãe foi olhar a prova e disse: "Bom, nem eu entendo do jeito que tá escrito isso aqui [...]". E me ensinou a fazer tudinho aquilo com regra de três, sem usar a fórmula. Óooooo [faz como um solfejo], muito fácil, nem estava acreditando. Dai na próxima prova eu fui lá e consegui resolver todinhos os cálculos e adivinha: zerei a prova de novo. A professora não aceitou a forma que eu fiz, ela queria a aplicação da fórmula. Dai minha mãe foi chamada no colégio [...]. Chegamos em casa e ela disse: "Decora essa merda dessa fórmula, desenvolve essas questões com a fórmula e do lado tu faz com a regra de três para colocar o resultado, porque aquela mulher insiste que tu tem que usar essa fórmula mesmo eu dizendo para ela que tu nunca vai usar essa fórmula na vida, nem no vestibular". Dai na outra prova eu fiz [...], levei duas horas a mais na prova, mas fiz. E tirei 10. Dai quando cheguei com o resultado em casa, a mãe disse: "Minha filha, aprende uma coisa, às vezes tu tem que contornar o mundo, não adianta tu bater de frente com ele”. Essa foi minha grande aprendizagem para a vida [...].

No diálogo que se seguiu a esse relato e em outros, nos quais Fiona fala sobre suas experiências de aprendizagem, com frequência ela relata como aprendizagens significativas aquelas não relacionadas à escola, que acontecem em espaços mais flexíveis e nos quais ela tem maior liberdade para expressar-se, como no caso do teatro, por exemplo. Desse modo, compreende-se que ela foi configurando subjetivamente a aprendizagem como um processo amplo, do qual ela era agente e no qual ocupava um espaço simbólico de quem podia aprender. Fiona sente necessidade de aprender, é curiosa e constantemente está estudando e aprendendo coisas novas.

Watusi foi subjetivando a aprendizagem muito em função da relação com a mãe, que lhe ensinava sobre a cultura africana e sobre como fazer as tarefas da casa a partir da oralidade e do exemplo, segundo ele. Contando sobre suas aprendizagens, ele ressalta: “O ratinho [seu

${ }^{6} \mathrm{O}$ termo aprendente, assim como ensinante, tem o valor de conceito para a Psicopedagogia, segundo Fernández (2001). Não é o mesmo que utilizar os termos aluno e professor, que se referem a lugares objetivos em uma relação pedagógica, mas diz respeito a um sujeito que aprende, aprendizagem humana.

RIAEE - Revista Ibero-Americana de Estudos em Educação, Araraquara, v. 15, n. esp. 3, p. 2411-2428, nov., 2020. E-ISSN: 1982-5587 
primeiro mestre de capoeira] nos ensinava sobre a vida, sobre orçamento participativo, sobre organização comunitária. Ele se sentava com a gente e contava sobre história [...]", lembra com afeto e expressa sentidos subjetivos produzidos através da emoção de reviver o momento em memória.

A experiência de escolarização de Watusi foi difícil, ele tinha dificuldades em adaptarse ao modelo rígido, não tinha materiais e não lembra daquele tempo com uma afetividade mais positiva. Contudo, as aprendizagens da capoeira, no projeto social que participava, e as aprendizagens com a mãe, permitiram que Watusi configurasse o aprender como processo de vida. No completamento de frases ele diz: “Aprender é: refletir, questionar e pôr em prática de maneira construtiva o que aprendeu independentemente do contexto". Watusi é um adulto curioso, falante, sensível e humilde. Sempre destaca a escuta como algo essencial para um educador, e suas práticas, de acordo com o relato de suas(seus) educandas(os), corroboram essa postura.

As configurações subjetivas de Fiona e de Watusi relacionadas à aprendizagem permitem pensar que eles compreendem a complexidade do aprender, subjetivam-no como um processo de vida, como possibilidade e, por isso, percebem o potencial que suas(seus) educandas(os) têm para aprender. Isso, de algum modo, promove uma postura de ensinante que permite a circulação do grupo entre os papéis de ensinante e de aprendente, o que cria um espaço de diálogo potente para que todos, de diferentes formas, aprendam e ensinem (FERNÁNDEZ, 2001).

As práticas que refletem esse posicionamento dialógico de Fiona e de Watusi tendem a estar mais articuladas com a realidade das(os) educandas(os), pois não são propostas fechadas que levam em conta apenas o que pensa a(o) educadora(or). Além da possibilidade de diálogo dentro dos espaços de Educação Social, em diferentes momentos Fiona e Watusi falam sobre a importância de conhecer suas(seus) educandas(os) e o contexto. Watusi diz:

Por isso eu gostava de ficar na frente da instituição [...] eu gostava de ficar lá na frente comendo sacolé, vendo o movimento das crianças, comendo bala com elas. Ali eu conhecia a fulana de verdade [...], eu conhecia as famílias [...].

Watusi conhecia a comunidade, gostava de acompanhar as crianças até à casa delas quando necessário. Fiona, por sua vez, fala sobre a importância das visitas domiciliares, sobre conversar com as famílias e ter uma relação aberta e permeada de diálogo com as(os) jovens com os quais trabalha. Nesse sentido, ela diz: 
Esses dias recebi uma [jovem] aqui na salinha, ficamos um tempão falando sobre o fim do namoro dela. A gente acaba fazendo esse papel de conselheira às vezes, de ouvidos. [...] Esse acaba sendo um espaço seguro para se exporem.

A partir desse trecho, pode-se refletir sobre como o diálogo promove vínculo e o vínculo promove diálogo, constituindo-se de modo complexo no espaço relacional no qual ocorrem os processos educativos no ambiente de trabalho de Fiona. Estar aberta a conhecer sua(seu) educanda(o), engajada subjetivamente no processo educativo com o público que atende, parece ser fulcral, tanto no caso de Fiona quanto no de Watusi, para a constituição de um fazer dialógico.

Assim, o respeito que Fiona e Watusi têm pelas(os) suas(seus) educandas(os), o reconhecimento de sua humanidade, bem como o fato de configurarem subjetivamente o aprender como um processo de vida, que não se trata de uma imposição de saberes, mas um processo de construção que implica a pessoa como um todo, de modo complexo, são fatores que promovem um fazer dialógico (ROCHA, 2020). Essa dialogicidade, por sua vez, tem potencial para engajar as(os) educandas(os) no processo educativo social, tendo em vista que: conhece $\mathrm{a}(\mathrm{o})$ educanda(o), respeita as diferenças, reconhece os saberes e, por meio do diálogo, propõe processos de ensinar e aprender mais flexíveis, nos quais todos os participantes são ativos.

A pesquisa realizada apontou alguns possíveis caminhos para que se pense a formação de educadoras(es) sociais com fazeres que sejam promotores de aprendizagens significativas para o público ao qual atende. No que tange ao fazer dialógico e ao recorte feito aqui, destacamse alguns desses caminhos como possibilidades e são apontados outros para novas pesquisas.

Destaca-se, à guisa de conclusões, que uma formação para educadoras(es) sociais, em qualquer nível, precisa:

a) promover conhecimento sobre aprendizagem em uma perspectiva de produção humana, dissociando o aprender e o ensinar do processo de escolarização (ROCHA, 2016);

b) promover conhecimento histórico de modo que educadoras(es) sociais possam compreender mais profundamente as expressões da Questão Social, configurando subjetivamente suas(seus) educandas(os) de modo descolado da subjetividade social produzida hegemonicamente acerca delas(es);

c) promover conhecimento, debate e reflexão sobre a importância das relações, do diálogo e da circulação entre os papéis de ensinar e de aprender nos processos educativos, confrontando, de modo crítico, tais conhecimentos com a realidade;

RIAEE - Revista Ibero-Americana de Estudos em Educação, Araraquara, v. 15, n. esp. 3, p. 2411-2428, nov., 2020. E-ISSN: 1982-5587 
d) promover experiências que contemplem a diversidade cultural e as experiências estéticas, pois a arte como expressão da própria cultura (VYGOTSKY, 1999), no decurso da experiência estética que proporciona, tem potencial para provocar tensionamentos importantes entre diferentes configurações subjetivas e, portanto, pode contribuir de modo significativo para a constituição subjetiva de educadoras(es) sociais em uma perspectiva de criticidade e sensibilidade;

e) valorizar diferentes culturas e saberes, tendo em vista que a formação de educadoras(es) sociais precisa considerar e, de algum modo, evidenciar, diferentes culturas, pois o próprio público atendido é diverso e tende a distanciar-se da realidade vivida pelos autores majoritariamente utilizados na academia;

f) considerar o desenvolvimento subjetivo de educadoras(es) sociais, de modo que possam emergir como agentes e sujeitos, capacidade que parece ser fundamental para que transcendam as informações prontas e gerem ideias próprias no percurso de aprender e de ensinar (ALMEIDA; MITJÁNS MARTÍNEZ, 2019).

\section{Considerações finais}

Ao tecer as reflexões possíveis nestas poucas páginas sobre a potência e a complexidade de um fazer dialógico e, portanto, sobre os desafios que se apresentam a partir de tais reflexões, instauram-se inúmeras novas provocações a respeito do campo da Educação Social, da formação e das práticas de educadoras(es) sociais. O que se tem construído até o momento, conforme já salientado, são compreensões que não se pretende que sejam conceitos estáticos. Entende-se a produção de ciência como construção parcial e em movimento, que constantemente provoca novas inteligibilidades sobre a experiência humana em diferentes campos.

A partir da articulação das pesquisas nas quais este artigo se embasa, compreende-se que um fazer dialógico por parte de educadoras(es) sociais tem grande potencial para promover processos educativos, de ensinar e de aprender, mais flexíveis e que abarquem as diferenças, as necessidades, os interesses, os saberes e os contextos de educandas(os). Contudo, os processos formativos dessas(es) trabalhadoras(es) precisam comprometer-se com uma formação mais humana e menos tecnicista, que promova uma série de conhecimentos articulados com experiências no campo, já que é na experiência vivida que os indivíduos são impactados, compreendendo de modo mais aprofundado a teoria e produzindo subjetividade, tendo a 
possibilidade de gerar vias alternativas à subjetividade social dominante (GONZÁLEZ REY; MITJÁNS MARTÍNEZ, 2017).

AGRADECIMENTOS: À Coordenação de Aperfeiçoamento de Pessoal de Nível Superior (CAPES) pelo financiamento da pesquisa a partir da bolsa de doutorado CAPES/PROEX.

\section{REFERÊNCIAS}

ADORNO, T. W. Educação e emancipação. São Paulo: Paz e Terra, 1995.

ALMEIDA, P.; MITJÁNS MARTÍNEZ, A. A configuração subjetiva da ação do aprender: um estudo de caso sobre o aluno em seu momento de ingresso no ensino superior. Revista Obutchénie, Brasília, v. 3, n. 1, p. 88-113, set. 2019. Disponível em:

http://www.seer.ufu.br/index.php/Obutchenie/article/view/50592. Acesso em: 10 set. 2020.

ARENDT, H. A condição humana. Rio de Janeiro: Forense Universitária, 2014.

DEL POZO SERRANO, F. J. Pedagogía social en Colombia: entre la experiencia de la educación popular y el reto de la investigación-acción en la profesionalización socioeducativa de un país en posconflicto. Ensino \& Pesquisa, União da Vitória, v. 15, n. 2, p. 97-116, jul. 2017.

FERNÁNDEZ, A. Os idiomas do aprendente: análise de modalidades ensinantes em famílias, escolas e meios de comunicação. Porto Alegre: Artmed, 2001.

GONZÁLEZ REY, F. Sujeto y subjetividad: una aproximación histórico cultural. México: Thomson Eds., 2002.

GONZÁLEZ REY, F. Subjetividade, complexidade e pesquisa em psicologia. São Paulo: Thompson Learning, 2005.

GONZÁLEZ REY, F. A configuração subjetiva dos processos psíquicos: avançando na compreensão da aprendizagem como produção subjetiva. In: MITJÁNS MARTÍNEZ, A.; SCOZ, B. J. L.; CASTANHO, M. I. S. (Org.). Ensino e aprendizagem: a subjetividade em foco. Brasília: Liber Livro, p. 21-42, 2012a.

GONZÁLEZ REY, F. O social na psicologia e a psicologia no social: a emergência do sujeito. 3. ed. Petrópolis: Vozes, 2012 b.

GONZÁLEZ REY, F. Relación entre lo teórico y lo empírico. In: GONZÁLEZ REY, F.; QUEVEDO, J. E. M. Subjetividad, cultura e investigación cualitativa: los antecedentes desde la personalidad y el método clínico. Bogotá: Editorial Aula de Humanidades, 2017. p. 251-266.

GONZÁLEZ REY, F. The Rescue of Subjectivity from a Cultural Historical Standpoint. In: BESHARA, R. K. (Ed.). A critical introduction to psychology. Hauppauge: Nova Science Publishers, 2020. p. 8-26.

RIAEE - Revista Ibero-Americana de Estudos em Educação, Araraquara, v. 15, n. esp. 3, p. 2411-2428, nov., 2020. E-ISSN: 1982-5587 
GONZÁLEZ REY, F.; MITJÁNS MARTÍNEZ, A. Subjetividade: teoria, epistemologia e método. Campinas: Alínea, 2017.

JOHANN, J. R. Educação e a utopia da esperança. Canoas: Ed. ULBRA, 2008.

MITJÁNS MARTÍNEZ, A. A teoria da subjetividade de González Rey: uma expressão do paradigma da Complexidade na Psicologia. In: GONZÁLEZ REY, F. (Org). Subjetividade, complexidade e pesquisa em psicologia. São Paulo: Thompson Learning, 2005. p. 1-25.

PEREIRA, A. A profissionalidade do educador social frente a regulamentação profissional da educação social: as disputas em torno do projeto de lei 5346/2009. Revista Ibero-Americana de Estudos em Educação, Araraquara, v. 11, n. 3, p. 1294-1317, 2016. Disponível em: https://periodicos.fclar.unesp.br/iberoamericana/article/view/6041/5910. Acesso em: 8 set. 2020.

ROCHA, J. S. O aprender como produção humana: os sentidos subjetivos produzidos acerca da aprendizagem por adolescentes em situação de vulnerabilidade social. Orientadora: Marlene Rozek. 2016. 217 f. Dissertação (Mestrado em Educação) - Pontifícia Universidade Católica do Rio Grande do Sul, Porto Alegre, 2016.

ROCHA, J. S. A constituição subjetiva de educadoras(es) sociais: tornar-se educador(a) no processo de vida. 2020. 228 f. Tese (Doutorado em Educação) - Pontifícia Universidade Católica do Rio Grande do Sul, Porto Alegre, 2020.

ROCHA, J. S.; DI FRANCO, A. A aprendizagem em contexto de vulnerabilidade social. In: ROZEK, M.; DOMINGUES, C. L. K. (Org.). As dificuldades de aprendizagem e o processo de escolarização. Porto Alegre: EDIPUCRS, 2017. p. 165-194.

ROCHA, J. S.; LEMOS, M. S.; ALVES, T. P. Aprendizagem: como educadora e educador social, o que é fundamental saber sobre o tema? In: MONTEIRO, S. A. S. (Org.). Filosofia, política, educação, direito e sociedade. Ponta Grossa: Editora Atena, 2019. v. 6. p. 295-306.

SANTOS, C.; PAZINATO, E.; NASCIMENTO, N.; DONATO, R. S.; ENGELMAN, T. Índice de compliance de atividade policial (ICAP) no contexto do monitoramento do uso da força nos territórios do Programa de Oportunidade e Direitos no Estado do Rio Grande do Sul. In: ENCONTRO NACIONAL DE ENSINO E PESQUISA NO CAMPO DE PÚBLICAS, 3., 2019, Natal. Anais [...] Natal: Universidade Federal do Rio Grande do Norte, 2019. p. 2011-2026.

Disponível em:

https://zone.inatto.com/acp.root/acp_data/anais2020/trabalhos/st13/09_indice_de_compliance _da_atividade_policial_(i.pdf. Acesso em: 8 set. 2020.

SOWA, A.; ROSA, R. Programa Mais Cultura nas Escolas: desafios e possibilidades para a construção de sujeitos inter/transculturais. In: CONGRESSO DE CIÊNCIAS DA COMUNICAÇÃ̃ NA REGIÃO SUL, 15., 2014, Palhoça. Anais [...]. São Paulo: Intercom, 2014. p. 1-12.

Disponível em: https://portalintercom.org.br/anais/sul2014/resumos/R40-1103-1.pdf. Acesso em: 8 set. 2020.

ÚCAR, X. Pedagogías de lo social. Barcelona: Editorial UOC, 2016.

RIAEE - Revista Ibero-Americana de Estudos em Educação, Araraquara, v. 15, n. esp. 3, p. 2411-2428, nov., 2020. E-ISSN: 1982-5587 
ÚCAR, X. Pedagogía social en Europa y América Latina: diálogos e interacciones en el marco de lo común. In: DEL POZO SERRANO, F. J. Pedagogía social en Iberoamérica: fundamentos, ámbitos y retos para la acción socioeducativa. Barranquilla: Editorial Universidad del Norte, 2018. p. 3-33.

VISCA, J. Técnicas proyetivas psicopedagógicas. 4. ed. Buenos Aires: Visca \& Visca, 2002.

VYGOTSKY, L. Psicologia da arte. São Paulo: Martins Fontes, 1999.

ZUCCHETTI, D. T.; SEVERO, J. L. R. L. As dimensões tempo e espaço em práticas de educação integral: implicações curriculares a partir do diálogo entre Paulo Freire e Darcy Ribeiro. Revista Ibero-Americana de Estudos em Educação, Araraquara, v. 15, n. 2, p. 560-577, abr./jun. 2020. Disponível em:

https://periodicos.fclar.unesp.br/iberoamericana/article/view/12467. Acesso em: 8 set. 2020.

\section{Como referenciar este artigo}

ROCHA, J. S.; ROZEK, M. A potência e a complexidade de um fazer dialógico: desafios da formação e da atuação de educadoras(es) sociais. Revista Ibero-Americana de Estudos em Educação, Araraquara, v. 15, n. esp. 3, p. 2411-2428, nov., 2020. E-ISSN: 1982-5587. DOI: https://doi.org/10.21723/riaee.v15iesp3.14449

Submetido em: 20/07/2020

Revisões requeridas em: 30/08/2020

Aprovado em: 29/09/2020

Publicado em: 30/10/2020 